\title{
Intradural Route of Administration
}

National Cancer Institute

\section{Source}

National Cancer Institute. Intradural Route of Administration. NCI Thesaurus. Code C38242.

Administration of a drug within or beneath the dura mater. 